\title{
Chronic Obstructive Pulmonary Disease Increases the Risk of New-onset Atrial Fibrillation and Mortality of Patients with Atrial Fibrillation
}

Shinjeong Song, MD; Pil-Sung Yang, MD; Tae-Hoon Kim, MD; Jae-Sun Uhm, MD, PhD; Hui-Nam Pak, MD, PhD; Moon-Hyoung Lee, MD, PhD; Boyoung Joung, MD, PhD

Division of Cardiology, Yonsei University College of Medicine, Seoul, Republic of Korea
Received: November 9, 2017

Revision Received: December 6, 2017

Accepted: December 20, 2017

Correspondence: Boyoung Joung, MD, PhD

Professor of Medicine, Yonsei Cardiovascular

Hospital, Yonsei University College of Medicine

50 Yonseino, Seodaemun-gu, Seoul, 03722,

Republic of Korea

Tel: +82-2-2228-8460 FAX: +82-2-2227-7732

E-mail: cby6908@yuhs.ac

Copyright (C) 2017 The Official Journal of Korean Heart Rhythm Society Editorial Board and EUM \& Communications

\begin{abstract}
Background: Although a few previous studies have analyzed the role of reduced lung function in predicting atrial fibrillation (AF), the relationship between the incidence of $\mathrm{AF}$ and comorbid chronic obstructive pulmonary disease (COPD) is unclear. We hypothesized that COPD is associated with the occurrence of new-onset AF and clinical outcomes in AF patients.
\end{abstract}

Methods: We analyzed the development of new-onset AF in 501,668 patients without AF and clinical outcomes in 4,541 patients with AF using Korean National Health Insurance Service-National Sample Cohort (NHIS-NSC).

Results: Comorbid COPD was found in $4.8 \%(11,442$ of 501,668$)$ of non-AF patients and $18.6 \%$ (820 of 4,541) of AF patients. The incidence of $\mathrm{AF}$ in COPD patients was significantly higher compared to non-COPD patients $(2.6 \%$ vs. $0.6 \%, p<0.001)$ over the follow-up period (45.5 \pm 14.9 months). In a multivariate Cox regression analysis, COPD predicted higher risk of AF independently from other risk factors (HR: 1.41, 95\% Cl: 1.25-1.60, $p<0.001)$. The allcause mortality of AF patients with COPD was significantly higher in patients who used b-blockers (20.6\% vs $13.1 \%$ during follow-up, $p<0.008)$. Multivariate Cox regression analysis showed that COPD is still an independent risk factor for all-cause mortality (HR: 1.25, 95\% Cl: 1.03-1.51, $p=0.022)$, and stroke (HR: $1.19,95 \% \mathrm{Cl}: 1.00-$ $1.41, p=0.039$ ).

Conclusion: The presence of COPD is an independent risk factor for new-onset AF. COPD is independently associated with all-cause mortality and stroke in AF patients.

Key Words: - Atrial Fibrillation Chronic Obstructive Pulmonary Disease -Incidence -Mortality 


\section{Introduction}

Atrial fibrillation (AF) is the most common sustained arrhythmia ${ }^{1}$ and confers an independent risk of stroke and death. ${ }^{2}$ A recent retrospective study showed that of comorbid chronic obstructive pulmonary disease (COPD) was associated with an increased likelihood of arrhythmia. Furthermore, it remained a significant predictor of AF/Atrial flutter (AFL) $(p<0.0001)$ after adjusting for other clinical factors. ${ }^{3}$ The prevalence of cardiovascular diseases (CVD) was higher in the COPD group than the control group in one retrospective cohort study. ${ }^{4}$ But the risk of stroke or mortality associated with COPD in patients with AF is not well known. We hypothesized that COPD is associated with the occurrence of new-onset AF and clinical outcomes in AF patients.

\section{Methods}

The institutional review board of Severance Hospital at Yonsei University College of Medicine in Seoul, Republic of Korea approved this study. The institutional review board waived the requirement to obtain informed consent.

To assess the association of COPD and all-cause mortality, cardiovascular mortality, and stroke in AF patients, we used data derived from the Korean NHIS-NSC cohort consisting of 1,025,340 Koreans from 2002 and followed the subjects until 2013. The National Health Insurance Service (NHIS) is the single insurer managed by the Korean government and the majority of the Korean population (97.1\%) are mandatory subscribers, with the remaining $3 \%$ of the population being medical aid subjects. All insured individuals and their dependents are required to undergo a periodic (i.e., mostly biennial) general health examination. The NHIS maintains a large health dataset and provides periodic updates on health-related risk factors and baseline biochemical data. ${ }^{5}$ We enrolled patients older than 18 years with health examination data from the NHIS-NSC after 2009. Participants who had missing data concerning comorbidities and laboratory results were excluded. Finally, we evaluated 506,805 participants of the NHIS-NSC and performed follow-up for adverse cardiovascular events and death until December 31, 2013 (Figure 1). The authors confirmed diagnoses using the International Classification of Disease, Tenth
Revision, Clinical Modification (ICD-10-CM) codes.

We examined the incidence of AF by dividing non-AF patients according to COPD by cohort enrollment to determine the effects of COPD on the occurrence of AF. We used an operational definition to extract data on COPD patients because pulmonary function test (PFT) results were not available in the NHIS-NSC. We searched for subjects with a diagnosis of COPD based on International Classification of Diseases-Tenth Revision (ICD-10) codes and medications prescribed. COPD patients were defined as subjects who met the following 2 criteria: 1 ) subjects with a diagnosis of ICD-10 codes for COPD or emphysema (J42, J43 [except for J43.0], J44) and 2) subjects with a prescription of more than 1 of the following COPD drugs at least twice per year: long-acting muscarinic antagonists, longacting beta- 2 agonists, inhaled corticosteroids, short-acting muscarinic antagonists, short acting beta- 2 agonists, or methylxanthine (>1 months). ${ }^{6}$

AF was identified using the International Classification of Disease 10th Revision (ICD-10) codes; I48 (atrial fibrillation and atrial flutter), I48.0 (atrial fibrillation), and I48.1 (atrial flutter). Diagnosis was established based on one inpatient or two outpatient records of ICD-10 codes in the database to ensure accuracy. ${ }^{78}$ To evaluate the accuracy of our definition of AF, we conducted a validation study in two hospitals with 628 randomly chosen patients with the ICD-10 code I48. Their electrocardiograms (ECGs) were reviewed by two physicians (DHK and JBP). The patients were determined to have AF if it was documented by ECG examinations. The positive predictive value was $94.1 \%$.

The primary clinical outcomes were all-cause mortality, cardiovascular mortality, and ischemic stroke. The dates and causes of death were obtained from the qualification data in the cohort database, which was prepared by Statistics Korea. Cardiovascular mortality was defined as death from a disease of the circulatory system. Causes of cardiovascular mortality were further categorized as MI, stroke any diagnosis of ischemic stroke with concomitant brain imaging studies, including CT or MRI was defined as incident ischemic stroke. The accuracy of the diagnosis of an ischemic stroke in the NHIS claim data has been previously validated. ${ }^{5}$

Propensity-score matching was used to reduce potential selection bias associated with an observational study. The cases 


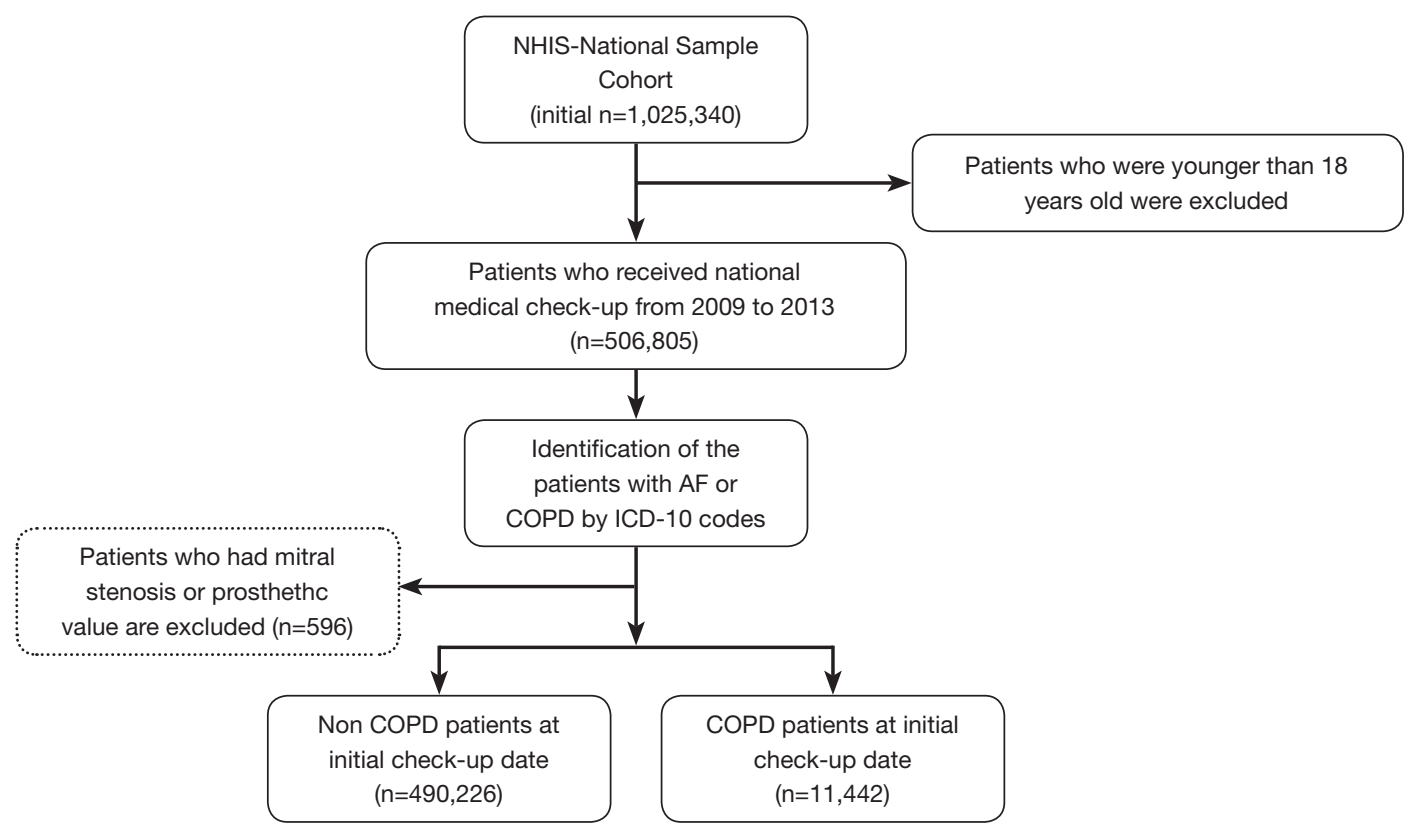

Figure 1. Flow chart of study population from the Korean National Health Insurance Service - National Sample Cohort (NHIS-NSC) Event follow-up was conducted after patient's first visit date for national medical check-up. Mean follow-up duration: $45.5 \pm 14.9$ months.

AF, atrial fibrillation; COPD, chronic obstructive pulmonary disease; ICD-10, International Classification of Diseases 10th Revision; NHIS, National Health Insurance Service of South Korea

were matched (without replacement) with controls with a ratio of 1:1 based on the closest possible value of the propensity score (nearest neighbor matching).

Continuous variables were expressed as mean \pm standard deviation and categorical variables as counts and percentages. A student's $t$-test for continuous variables or Chi-square test for categorical variables was used to determine the significance of differences in variables between 2 groups. All-cause mortality and cardiovascular mortality were analyzed using the Kaplan-Meier survival analysis and multivariable Cox-proportional hazard models were applied to determine if there were independent associations between COPD and clinical outcomes.

A $p$ value $<0.05$ was considered statistically significant. Statistical analyses were performed using the Statistical Package for the Social Sciences 23.0 (SPSS 23.0; IBM Corp., Armonk, NY, USA).

\section{Results}

Table 1 shows the baseline characteristics of the study population (COPD group: $n=11,771$, non-COPD group: $n=483,650$, overall: $n=495,421)$ from the NHIS-NSC. The subjects in the COPD group were older $(64.1 \pm 12.8$ vs. $47.4 \pm 14.2, p<0.001)$ and had higher body mass index $(24.9 \pm 3.5$ vs. $23.7 \pm 3.3, p<0.001)$ than those in the non-COPD group. Compared to the non-COPD patients, COPD patients were more likely to have comorbidities, such as congestive heart failure (CHF), diabetes mellitus, cerebral vascular accident (CVA) or transient ischemia attack (TIA) vascular disease, hypertension, hyperlipidemia, and CKD (all $p<0.001$ ). After propensity score matching, we identified 11,755 patients with COPD and 11,755 matched controls without COPD. These 2 groups were well balanced (balance defined as absolute value of standardized difference less than 0.1) and had similar baseline characteristics.

In this study, 820 COPD patients with AF, and 10,622 COPD patients without $\mathrm{AF}$ were included. We investigated the difference of AF occurrence according to patients with or without COPD. Of the 11,771 patients who had COPD at the time of initial enrollment in NHIS-NSC, 303 were newly diagnosed with AF (2.6\%), and of the 483,650 patients who had no COPD, 3,113 were newly diagnosed with AF (0.6\%). This difference in incidence was statistically significant $(p<0.001)$. 
Table 1. Baseline characteristics of the study population

\begin{tabular}{|c|c|c|c|c|c|c|c|c|}
\hline & \multicolumn{4}{|c|}{ Overall population before propensity score-matching } & \multicolumn{4}{|c|}{ Propensity score-matched population } \\
\hline & $\begin{array}{c}\text { COPD } \\
(n=11,771)\end{array}$ & $\begin{array}{l}\text { Non-COPD } \\
(\mathrm{n}=483,650)\end{array}$ & $P$-value & $\begin{array}{l}\text { Standardized } \\
\text { difference }\end{array}$ & $\begin{array}{c}\text { COPD } \\
(n=11,755)\end{array}$ & $\begin{array}{l}\text { Non-COPD } \\
(n=11,755)\end{array}$ & $P$-value & $\begin{array}{c}\text { Standardized } \\
\text { difference }\end{array}$ \\
\hline Age (years) & $64.1 \pm 12.8$ & $47.4 \pm 14.2$ & $<0.001$ & 1.179 & $64.1 \pm 12.8$ & $63.9 \pm 13.3$ & 0.293 & 0.015 \\
\hline Men & $5,585(47.5 \%)$ & $239,903(49.6 \%)$ & $<0.001$ & -0.048 & $5,577(47.4 \%)$ & $5,588(47.5 \%)$ & 0.886 & -0.002 \\
\hline Body mass index $\left(\mathrm{kg} / \mathrm{m}^{2}\right)$ & $24.9 \pm 3.5$ & $23.7 \pm 3.3$ & $<0.001$ & 0.061 & $23.9 \pm 3.5$ & $24.0 \pm 3.3$ & 0.016 & -0.029 \\
\hline Waist (cm) & & & & 0.95 & & $0.22-4.08$ & & 0.95 \\
\hline Hypertension & $6,717(57.1 \%)$ & $102,478(21.2 \%)$ & $<0.001$ & 0.881 & $6,708(57.1 \%)$ & $6,816(58.0 \%)$ & 0.154 & -0.021 \\
\hline Diabetes mellitus & $4,314(36.7 \%)$ & $60,289(12.5 \%)$ & $<0.001$ & 0.773 & $4,307(36.7 \%)$ & $4,409(37.5 \%)$ & 0.168 & -0.021 \\
\hline Heart failure & $1,743(14.8 \%)$ & $10,569(2.2 \%)$ & $<0.001$ & 1.131 & $1,732(14.8 \%)$ & $1,596(13.6 \%)$ & 0.011 & 0.053 \\
\hline Dyslipidemia & $5,383(45.8 \%)$ & $91,661(19.0 \%)$ & $<0.001$ & 0.707 & $5,374(45.7 \%)$ & $5,508(46.9 \%)$ & 0.080 & -0.025 \\
\hline CKD & $1,950(16.6 \%)$ & 27,561 (5.7\%) & $<0.001$ & 0.656 & $1,941(16.5 \%)$ & $1,877(16.0 \%)$ & 0.258 & 0.022 \\
\hline Previous MI & 561 (4.8\%) & $4,473(0.9 \%)$ & $<0.001$ & 0.926 & 557 (4.7\%) & 522 (4.4\%) & 0.275 & 0.038 \\
\hline Previous stroke & $1,710(14.5 \%)$ & $17,478(3.6 \%)$ & $<0.001$ & 0.833 & $1,703(14.5 \%)$ & $1,672(14.2 \%)$ & 0.564 & 0.012 \\
\hline Malignancy & $2,408(20.5 \%)$ & $31,344(6.5 \%)$ & $<0.001$ & 0.723 & 2,395 (20.4\%) & 2,340 (19.9\%) & 0.371 & 0.016 \\
\hline Smoking history & 7,627 (64.8\%) & $301,686(62.4 \%)$ & $<0.001$ & 0.058 & 7,628 (64.9\%) & 7,603 (64.7\%) & 0.210 & 0.005 \\
\hline Current smoker & 2,046 (17.4\%) & $118,667(24.5 \%)$ & $<0.001$ & -0.240 & 2,046 (17.4\%) & 2,171 (18.5\%) & 0.210 & -0.040 \\
\hline
\end{tabular}

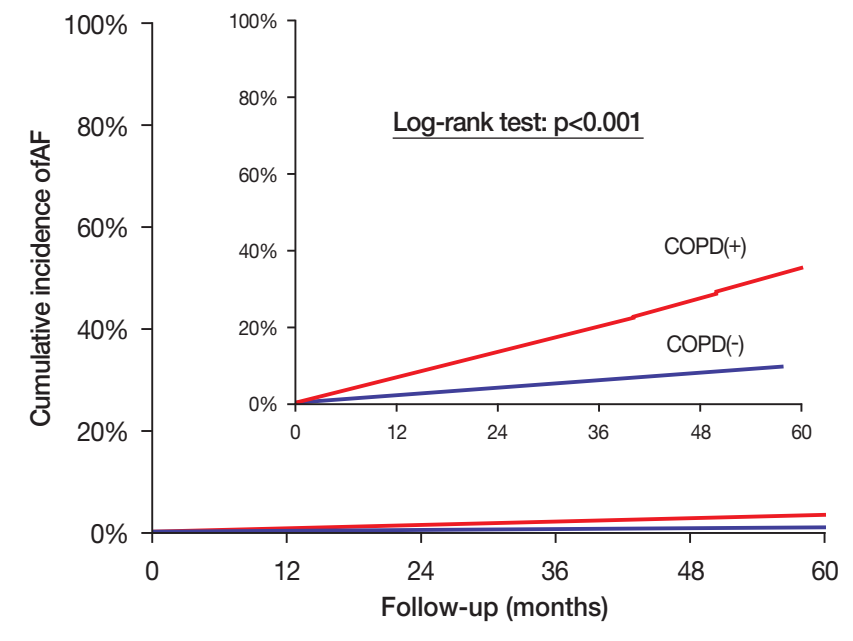

\begin{tabular}{ccccccc}
\hline $\begin{array}{c}\text { Number at Risk } \\
\text { (months) }\end{array}$ & 0 & 12 & 24 & 36 & 48 & 60 \\
\hline COPD(+) & 23,741 & 23,498 & 21,645 & 19,073 & 15,832 & 8,341 \\
COPD(-) & 475,651 & 474,425 & 438,839 & 389,981 & 324,822 & 195,395 \\
\hline
\end{tabular}

Figure 2. Kaplan-Meier survival curve according to chronic obstructive pulmonary disease (COPD) in overall papulation COPD, chronic obstructive pulmonary disease
The Kaplan-Meier cumulative AF curves according to the presence of COPD are presented in Figure 2. In the general population, cumulative incidence of atrial fibrillation was investigated according to the difference of AF occurrence. The incidence of $A F$ was significantly higher in the COPD group than in the non-COPD group (Figure 2; all log-rank $p<0.001$ ).

In addition, the relative risk of incident AF associated with COPD was graphically presented against the background of the conventional risk factors used in the multivariate adjusted Cox regression analysis (Figure 3). Conventional risk factors, such as age, male sex, increased waist circumference, hypertension, diabetes, heart failure, stroke or TIA, and history of smoking increased the risk of AF. The increase in estimated glomerular filtration rate (eGFR) was inversely correlated with the incidence of AF. The effect of BMI on AF was found to be neutral. In a multivariate model, COPD remained a significant risk factor for new-onset AF (hazard ratio [HR] 1.41, 95\% confidence interval [CI] $1.25-1.60, p<0.001)$. In the propensity score matched 


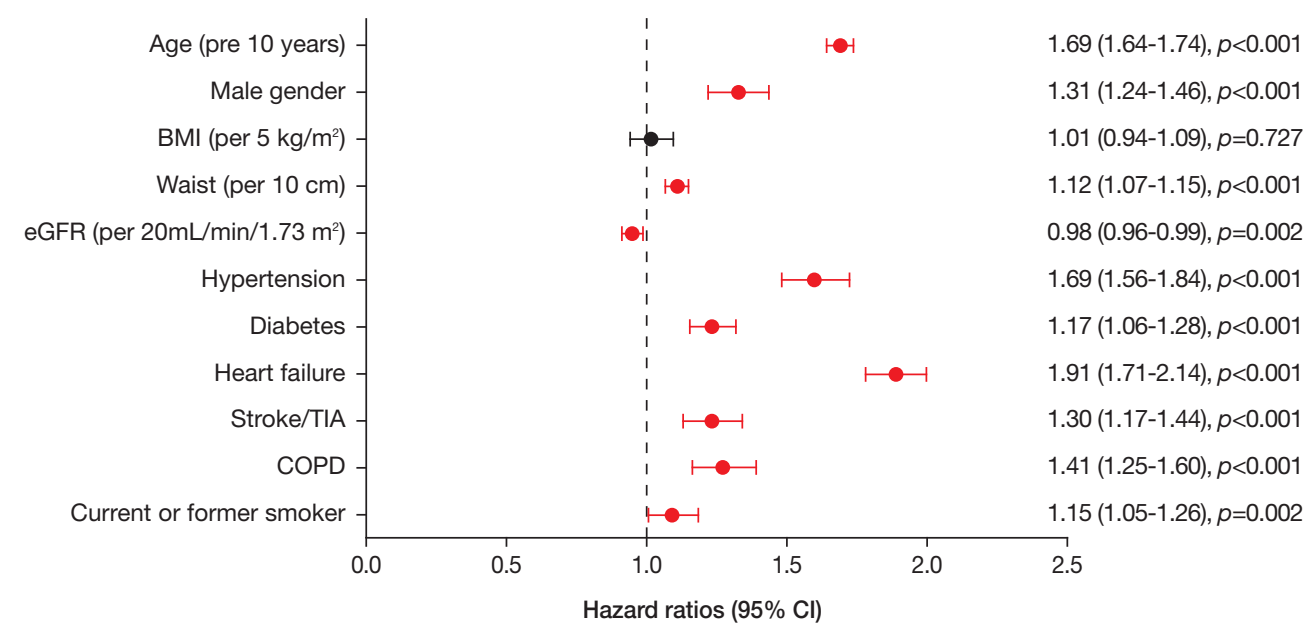

Figure 3. The relative risk of incident AF associated with COPD against the back-ground of the conventional risk factors used in the multivariate adjusted Cox regression analysis.

Covariates used in the model: age, gender, BMI, waist, eGFR (CKD EPI), systolic and diastolic blood pressure, hypertension, diabetes, heart failure, stroke/TIA, COPD, smoking ghistory.

$\mathrm{BMI}$, body mass index; COPD, chronic obstructive pulmonary disease; eGRF, estimated glomerular filtration rate; TIA, transient ischemic accident

Table 2. COPD and conventional risk factors in prediction of AF incident in a multivariate Cox proportional hazards model in propensity score-matched population.

\begin{tabular}{|c|c|c|c|c|}
\hline \multirow[b]{2}{*}{ Age (per 10 years) } & \multicolumn{2}{|c|}{$\begin{array}{l}\text { Overall population } \\
\text { before propensity score-matching }\end{array}$} & \multicolumn{2}{|c|}{ Propensity score-matched population } \\
\hline & $1.69(1.64-1.74)$ & $<0.001$ & $1.58(1.42-1.75)$ & $<0.001$ \\
\hline Male gender & $1.31(1.24-1.46)$ & $<0.001$ & $1.57(1.30-1.91)$ & $<0.001$ \\
\hline BMI (per 5 kg/m²) & $1.01(0.94-1.09)$ & 0.727 & $0.82(0.68-1.00)$ & 0.054 \\
\hline Waist (per $10 \mathrm{~cm}$ ) & $1.12(1.07-1.15)$ & $<0.001$ & $1.19(1.03-1.39)$ & 0.020 \\
\hline eGFR (per $20 \mathrm{~mL} / \mathrm{min} / 1.73 \mathrm{~m}^{2}$ ) & $0.98(0.96-0.99)$ & 0.002 & $0.87(0.78-0.96)$ & 0.007 \\
\hline Hypertension & $1.69(1.56-1.84)$ & $<0.001$ & $1.98(1.52-2.57)$ & $<0.001$ \\
\hline Diabetes & $1.17(1.06-1.28)$ & $<0.001$ & $1.1(0.88-1.40)$ & 0.376 \\
\hline Heart failure & $1.91(1.71-2.14)$ & $<0.001$ & $1.90(1.53-2.37)$ & $<0.001$ \\
\hline Stroke/TIA & $1.30(1.17-1.44)$ & $<0.001$ & $1.18(0.94-1.49)$ & 0.161 \\
\hline Current or former smoker & $1.15(1.05-1.26)$ & 0.002 & $1.14(0.89-1.46)$ & 0.287 \\
\hline COPD & $1.41(1.25-1.60)$ & $<0.001$ & $1.37(1.13-1.66)$ & 0.001 \\
\hline
\end{tabular}

population, COPD consistently increased the risk of AF (HR 1.37; 95\% CI 1.13-1.66) regardless of adjusting for potential confounding variables (Table 2).

The hazard ratio of AF was higher in patients with COPD who used beta-agonist-containing drugs (Table 3 ). In the propensity score matched population, the incidence of AF was higher in patients treated with drugs, including beta-agonists, is higher ( $\mathrm{HR}$ 1.46; $p=0.003$ ) compared to that in patients treated with other drugs (HR 1.31, $p=0.004)$.

We investigated the risk of all-cause mortality, cardiovascular 
Table 3. COPD and medication risk factors in prediction of AF incident in a multivariate Cox proportional hazards model in propensity score-matched population.

\begin{tabular}{lcccc}
\hline & Overall population before propensity score-matching & \multicolumn{2}{c}{ Propensity score-matched population } \\
\hline $\begin{array}{l}\text { COPD with medication except } \\
\text { systemic beta agonist }\end{array}$ & $1.38(1.20-1.59)$ & $<0.001$ & $1.31(1.09-1.58)$ & 0.004 \\
$\begin{array}{l}\text { COPD with medications includ- } \\
\text { ing systemic beta agonist }\end{array}$ & $1.47(1.17-1.84)$ & 0.001 & $1.46(1.14-1.88)$ & 0.003 \\
\hline
\end{tabular}

AF, atrial fibrillation ; COPD, comorbid chronic obstructive pulmonary disease

Table 4. Hazard ratio for all-cause mortality, cardiovascular mortality, and stroke of AF patients in a multivariate Cox proportional hazards model*. $^{*}$.

\begin{tabular}{|c|c|c|c|c|c|c|}
\hline & \multicolumn{2}{|c|}{ All-Cause Mortality } & \multicolumn{2}{|c|}{ Cardiovascular Mortality } & \multicolumn{2}{|l|}{ Stroke } \\
\hline & $\mathrm{HR}(95 \% \mathrm{Cl})$ & $P$-value & $\mathrm{HR}(95 \% \mathrm{Cl})$ & $P$-value & $\mathrm{HR}(95 \% \mathrm{Cl})$ & $P$-value \\
\hline Age (years) & $1.08(1.07-1.09)$ & $<0.001$ & $1.11(1.11-1.12)$ & $<0.001$ & $1.05(1.05-1.06)$ & $<0.001$ \\
\hline Female gender & $0.69(0.59-0.82)$ & $<0.001$ & $0.60(0.52-0.69)$ & $<0.001$ & - & - \\
\hline BMI $\left(\mathrm{kg} / \mathrm{m}^{2}\right)$ & $0.86(0.83-0.89)$ & $<0.001$ & $0.90(0.89-0.92)$ & $<0.001$ & - & - \\
\hline Waist (cm) & $1.02(1.01-1.03)$ & 0.007 & - & - & - & - \\
\hline eGFR (mL/min/1.73 m²) & $0.86(0.83-0.89)$ & $<0.001$ & $0.99(0.98-0.99)$ & $<0.001$ & - & - \\
\hline Hypertension & - & - & $1.73(1.49-2.60)$ & $<0.001$ & $1.18(1.00-1.38)$ & 0.046 \\
\hline Diabetes & $1.46(1.23-1.74)$ & $<0.001$ & $1.32(1.15-1.53)$ & $<0.001$ & $1.26(1.09-1.45)$ & 0.001 \\
\hline Heart failure & - & - & $2.24(1.93-2.60)$ & $<0.001$ & - & - \\
\hline Stroke/TIA history & - & - & $1.78(1.55-2.04)$ & $<0.001$ & $1.91(1.68-2.17)$ & $<0.001$ \\
\hline Current/former smoker & - & - & $1.19(1.03-1.38)$ & 0.019 & $1.22(1.08-1.39)$ & 0.002 \\
\hline COPD & $1.25(1.03-1.51)$ & 0.022 & - & - & $1.19(1.01-1.41)$ & 0.039 \\
\hline
\end{tabular}

*Models were adjusted for age, gender, BMI, waist, eGFR (CKD EPI), systolic and diastolic blood pressure, hypertension, diabetes, heart failure, stroke/TIA history, COPD, smoking history with backward stepwise selection.

$\mathrm{AF}$, atrial fibrillation; BMI, body mass index; COPD, comorbid chronic obstructive pulmonary disease; eGFR, estimated glomerular filtration rate; TIA, transient ischemia attack

mortality, and stroke in AF patients using multivariate Cox proportional hazards model (Table 4). After adjusting the variables that influenced the outcomes of patients with AF, COPD was still an independent risk factor both all-cause mortality (hazard ratio [HR] 1.25, 95\% confidence interval [CI] 1.03-1.51, $p=0.022$ ) and stroke (HR 1.19, 95\% CI 1.00-1.41, $p<0.001)$, but was not an independent risk factor for cardiovascular mortality. Age and diabetes increased the risk of allcause mortality, cardiovascular mortality, and stroke after adjusting for all clinical variables.

\section{Discussion}

In this large, retrospective general population-based cohort study, we found that COPD was associated with higher newonset $\mathrm{AF}$ in the general population. Furthermore, COPD was an independent risk factor and associated with the risk for stroke as well as all-cause mortality in AF patients. Associations between COPD and stroke were significant after adjusting for variable clinical factors.

Our results showed that people with COPD have an 
approximately $20 \%$ increased risk of stroke, which was similar to findings from previous studies. ${ }^{9-12}$

To our knowledge, this is the first time that associations with $\mathrm{COPD}$ and $\mathrm{AF}$ and the major clinical outcomes were investigated in the general population. COPD is the fourth leading cause of mortality and morbidity in the world. ${ }^{13}$ This disease is characterized by chronic inflammation of the peripheral airways and lung parenchyma, which leads to progressive obstruction of the airways. Furthermore, increasing evidence indicates that COPD is a complex disease involving more than airflow obstruction.

Previous studies have shown the relation between COPD and CVD. Feary et al. reported that COPD was associated with a 3.98fold increased risk of CVD and 2.34-fold increased risk of stroke. ${ }^{14}$ Indeed, the majority of patients with COPD die because of CVD rather than respiratory failure. In mild to moderate COPD, cardiovascular events are the leading causes of hospitalization and mortality. ${ }^{15,16}$ The mechanisms by which pulmonary changes associated with COPD can lead to these cardiovascular events are not clear. Current studies are primarily focused on perturbed neurohumoral regulation and activated systemic inflammation. ${ }^{15}$

$\mathrm{AF}$ is the most common cardiac arrhythmia, occurring in $1 \%-2 \%$ of the general population. ${ }^{17}$ It is also a common cardiovascular morbidity and several studies have reported the adverse effect of AF on the prognosis of COPD patients, especially in the setting of acute exacerbation, wherein the presence of AF was an independent predictor of death. ${ }^{18-20}$

P. Buch et al. indicated that reduced lung function is an independent predictor of new-onset AF. The mechanisms underlying reduced lung function with AF is not clear. Some studies revealed that ectopic beats initiating AF often originate in the walls of the pulmonary veins, ${ }^{21}$ and it is possible that these could be triggered by changes in gas composition or pulmonary hypertension. In the present study, hypoxia and cor pulmonale only accounted for some of this effect as the relationship was also found in subjects with mild to moderately reduced forced expiratory volume in 1 second $\left(\mathrm{FEV}_{1}\right){ }^{22}$

The coexistence of COPD and AF is common and the interplay between the two is complex. COPD patients are at an increased risk of incident $\mathrm{AF}^{22-24}$ Additionally, the adverse effect of incident AF on the clinical outcomes in COPD has also been proposed. ${ }^{18,20}$

However, few studies have evaluated the influence of COPD on the prognosis of AF. To our knowledge, there has been no study that specifically addressed the risk prediction model for incident AF in COPD patients. Thus, to our knowledge, this is the first study to report on the effect of COPD on the outcomes in the general population.

The prognostic significance of COPD in patients with AF deserves critical attention. After multivariate adjustment in the Cox model in our study, patients with AF and COPD were associated with increased all-cause mortality and stroke compared to patients without COPD.

Our study confirmed and extended previous reports suggesting that COPD is an independent risk factor for mortality in patients with AF. The adverse influence of COPD on the heart in AF patients may be multifold, including hypoxia, hypercapnia, electrolyte disturbances, and increased blood viscosity, which may worsen cardiac function in the setting of concomitant CVD by increased cardiac burden and oxygen consumption, as well as increased risk of other arrhythmias besides AF.

Previous studies have described the pathophysiological mechanisms implicating COPD in AF. First, there are studies investigating the effects of hypoxia on atrial electrophysiology. The ARIC (Atherosclerosis Risk In Communities) study examined the corrected QT interval using the Framingham formula (QTc) as a predictor of AF and predicted that the extended QTc would increase AF risk by about 2-fold. ${ }^{25}$ The QTc interval reflects the atrial expiratory refractory period (AERP), suggesting that the QTc interval may be an atrial risk index associated with cardiovascular risk and cardiovascular-specific treatment strategy evaluation. ${ }^{26}$

Hypercapnia has also been implicated in AF occurrence in COPD. Hypercapnia causes a marked and uniform increase in atrial refractoriness and marked slowing of atrial conduction. ${ }^{27}$ COPD contributes to ventricular diastolic dysfunction. Left ventricular diastolic dysfunction is associated with the severity of the disease and may provide another possible pathophysiological mechanism for AF initiation and persistence. ${ }^{28-30}$ Oxidative stress and inflammation represent a major pathophysiological mechanism in COPD, but are also associated with $\mathrm{AF}$ initiation and permanent preservation. ${ }^{31-34}$

The use of short- or long-acting beta-agonists may increase the risk of $\mathrm{AF}$ in $\mathrm{COPD} .{ }^{35}$ Beta-agonist drugs can potentially cause arrhythmias because of their effects on chronotropy, 
depolarization and repolarization mediated by the b-adrenergic receptor. ${ }^{36}$ In this cohort, the higher Cox proportional hazards of $\mathrm{AF}$ in patients with COPD, particularly those who took beta agonists, is consistent with this.

This study has some limitations. First, this study is subjected to all the limitations inherent in a cohort analysis. Second, the risk of cardiovascular mortality and stroke in COPD patients with AF was calculated for a period of 5 years only. Therefore, increasing age, one of the strongest risk factors for cardiovascular mortality and stroke, could not be accounted for as time progressed. Third, detailed parameters reflecting lung function, such as $\mathrm{FEV}_{1}$, were unavailable. Finally, it is unlikely that all COPD patients were identified although we validated COPD based on disease codes and medication. Therefore, the prevalence rate of COPD was likely to have been underestimated in this study.

\section{Conclusions}

COPD was associated with increased incidence of AF, and increased mortality and incidence of stroke in patients with AF. After multivariate adjustment, COPD was still an independent risk factor for all-cause mortality and stroke, but not a risk factor for cardiovascular mortality.

\section{Sources of Funding}

This study was supported by a research grant from the Korean Heart Rhythm Society (KHRS 2017-1).

\section{Reference}

1) Heeringa J, van der Kuip DA, Hofman A, Kors JA, van Herpen G, Stricker BH, Stijnen T, Lip GY, Witteman JC. Prevalence, incidence and lifetime risk of atrial fibrillation: the Rotterdam study. Eur Heart J. 2006;27:949-953

2) Benjamin EJ, Wolf PA, D'Agostino RB, Silbershatz H, Kannel WB, Levy D. Impact of atrial fibrillation on the risk of death: the Framingham heart study. Circulation. 1998;98:946-952

3) Konecny T, Park JY, Somers KR, Konecny D, Orban M, Soucek F, Parker KO, Scanlon PD, Asirvatham SJ, Brady PA, Rihal CS. Relation of chronic obstructive pulmonary disease to atrial and ventricular arrhythmias. Am J Cardiol. 2014;114:272-277
4) Curkendall SM, Lanes S, de Luise C, Stang MR, Jones JK, She D, Goehring E Jr. Chronic obstructive pulmonary disease severity and cardiovascular outcomes. Eur J Epidemiol. 2006;21:803-813

5) Lee J, Lee JS, Park SH, Shin SA, Kim K. Cohort profile: The National Health Insurance Service-National Sample Cohort (NHIS-NSC), South Korea. Int J Epidemiol. 2017;46:e15

6) Kim C, Yoo KH, Rhee CK, Yoon HK, Kim YS, Lee SW, Oh YM, Lee SD, Lee JH, Kim KJ, Kim JH, Park YB. Health care use and economic burden of patients with diagnosed chronic obstructive pulmonary disease in Korea. Int J Tuberc Lung Dis. 2014;18:737-743

7) Chen SJ, Liu CJ, Chao TF, Wang KL, Chen TJ, Chou P, Wang FD, Lin SJ, Chiang CE. Dental scaling and atrial fibrillation: a nationwide cohort study. Int J Cardiol. 2013;168:2300-2303

8) Chao TF, Liu CJ, Tuan TC, Chen SJ, Wang KL, Lin YJ, Chang SL, Lo LW, Hu YF, Chen TJ, Chiang CE, Chen SA. Rate-control treatment and mortality in atrial fibrillation. Circulation. 2015;132:1604-1612

9) Curkendall SM, DeLuise C, Jones JK, Lanes S, Stang MR, Goehring E, Jr., She D. Cardiovascular disease in patients with chronic obstructive pulmonary disease, Saskatchewan Canada cardiovascular disease in COPD patients. Ann Epidemiol. 2006;16:63-70

10) Finkelstein J, Cha E, Scharf SM. Chronic obstructive pulmonary disease as an independent risk factor for cardiovascular morbidity. Int J Chron Obstruct Pulmon Dis. 2009;4:337-349

11) Schneider C, Bothner U, Jick SS, Meier CR. Chronic obstructive pulmonary disease and the risk of cardiovascular diseases. Eur $J$ Epidemiol. 2010;25:253-260

12) Sidney S, Sorel M, Quesenberry CP, Jr., DeLuise C, Lanes S, Eisner MD. COPD and incident cardiovascular disease hospitalizations and mortality: Kaiser Permanente Medical Care Program. Chest. 2005;128:2068-2075

13) Fang $X$, Wang $X$, Bai C. COPD in China: the burden and importance of proper management. Chest. 2011;139:920-929

14) Feary JR, Rodrigues LC, Smith CJ, Hubbard RB, Gibson JE. Prevalence of major comorbidities in subjects with COPD and incidence of myocardial infarction and stroke: a comprehensive analysis using data from primary care. Thorax. 2010;65:956-962

15) Sin DD, Man SF. Chronic obstructive pulmonary disease: a novel risk factor for cardiovascular disease. Can J Physiol Pharmacol. 2005;83:8-13

16) Barnes PJ, Celli BR. Systemic manifestations and comorbidities of COPD. Eur Respir J. 2009;33:1165-1185 
17) Chinitz JS, Castellano JM, Kovacic JC, Fuster V. Atrial fibrillation, stroke, and quality of life. Ann N Y Acad Sci. 2012;1254:140-150

18) Fuso L, Incalzi RA, Pistelli R, Muzzolon R, Valente S, Pagliari G, Gliozzi F, Ciappi G. Predicting mortality of patients hospitalized for acutely exacerbated chronic obstructive pulmonary disease. Am JMed. 1995;98:272-277

19) Steer J, Gibson J, Bourke SC. The decaf score: Predicting hospital mortality in exacerbations of chronic obstructive pulmonary disease. Thorax. 2012;67:970-976

20) Ryynanen OP, Soini EJ, Lindqvist A, Kilpelainen M, Laitinen T. Bayesian predictors of very poor health related quality of life and mortality in patients with COPD. BMC Med Inform Decis Mak. 2013;13:34

21) Olsson SB. Atrial fibrillation--where do we stand today? J Intern Med. 2001;250:19-28

22) Buch P, Friberg J, Scharling H, Lange P, Prescott E. Reduced lung function and risk of atrial fibrillation in the Copenhagen city heart study. Eur Respir J. 2003;21:1012-1016

23) Li J, Agarwal SK, Alonso A, Blecker S, Chamberlain AM, London SJ, Loehr LR, McNeill AM, Poole C, Soliman EZ, Heiss G. Airflow obstruction, lung function, and incidence of atrial fibrillation: the Atherosclerosis Risk In Communities (ARIC) study. Circulation. 2014;129:971-980

24) Fuster V, Ryden LE, Cannom DS, Crijns HJ, Curtis AB, Ellenbogen KA, Halperin JL, Le Heuzey JY, Kay GN, Lowe JE, Olsson SB, Prystowsky EN, Tamargo JL, Wann S, Task Force on Practice Guidelines ACoCAHA, Committee for Practice Guidelines ESoC, European Heart Rhythm A, Heart Rhythm S. ACC/AHA/ESC 2006 guidelines for the management of patients with atrial fibrillation-executive summary: a report of the American College of Cardiology/American Heart Association task force on practice guidelines and the European Society of Cardiology committee for practice guidelines (writing committee to revise the 2001 guidelines for the management of patients with atrial fibrillation). Eur Heart J. 2006;27:1979-2030

25) Mandyam MC, Soliman EZ, Alonso A, Dewland TA, Heckbert SR, Vittinghoff E, Cummings SR, Ellinor PT, Chaitman BR, Stocke K, Applegate WB, Arking DE, Butler J, Loehr LR, Magnani JW, Murphy RA, Satterfield S, Newman AB, Marcus GM. The QT interval and risk of incident atrial fibrillation. Heart rhythm. 2013;10:1562-1568

26) Nguyen KT, Gladstone RA, Dukes JW, Nazer B, Vittinghoff E,
Badhwar N, Vedantham V, Gerstenfeld EP, Lee BK, Lee RJ, Tseng $\mathrm{ZH}$, Olgin JE, Scheinman MM, Marcus GM. The QT interval as a noninvasive marker of atrial refractoriness. Pacing and clinical electrophysiology. 2016;39:1366-1372

27) Stevenson IH, Roberts-Thomson KC, Kistler PM, Edwards GA, Spence S, Sanders P, Kalman JM. Atrial electrophysiology is altered by acute hypercapnia but not hypoxemia: implications for promotion of atrial fibrillation in pulmonary disease and sleep apnea. Heart rhythm. 2010;7:1263-1270

28) Baum C, Ojeda FM, Wild PS, Rzayeva N, Zeller T, Sinning CR, Pfeiffer N, Beutel M, Blettner M, Lackner KJ, Blankenberg S, Munzel T, Rabe KF, Schnabel RB, Gutenberg Health Study investigators. Subclinical impairment of lung function is related to mild cardiac dysfunction and manifest heart failure in the general population. International journal of cardiology. 2016;218:298-304

29) Caram LM, Ferrari R, Naves CR, Tanni SE, Coelho LS, Zanati SG, Minicucci MF, Godoy I. Association between left ventricular diastolic dysfunction and severity of chronic obstructive pulmonary disease. Clinics. 2013;68:772-776

30) Eweda I, Hamada G. Concordance between Doppler and pulsedwave Doppler tissue imaging in estimation of the degree of left ventricular dysfunction and correlating it to the degree of chronic obstructive pulmonary disease. Journal of the Saudi Heart Association. 2016;28:15-21

31) Gan WQ, Man SF, Senthilselvan A, Sin DD. Association between chronic obstructive pulmonary disease and systemic inflammation: a systematic review and a meta-analysis. Thorax. 2004;59:574-580

32) Harada M, Van Wagoner DR, Nattel S. Role of inflammation in atrial fibrillation pathophysiology and management. Circ J. 2015;79:495-502

33) Huang CX, Liu Y, Xia WF, Tang YH, Huang H. Oxidative stress: a possible pathogenesis of atrial fibrillation. Medical hypotheses. 2009; $72: 466-467$

34) Kirkham PA, Barnes PJ. Oxidative stress in COPD. Chest. 2013;144:266-273

35) Wilchesky M, Ernst P, Brophy JM, Platt RW, Suissa S. Bronchodilator use and the risk of arrhythmia in COPD: part 2: reassessment in the larger Quebec cohort. Chest. 2012;142:305-311

36) Cazzola M, Imperatore F, Salzillo A, Di Perna F, Calderaro F, Imperatore A, Matera MG. Cardiac effects of formoterol and salmeterol in patients suffering from COPD with preexisting cardiac arrhythmias and hypoxemia. Chest. 1998;114:411-415 